\title{
Some Dietetic Factors in Leprosy with Special Reference to $B$ Avitaminosis
}

\author{
James A. K. BRown.
}

(Reprinted from the West African Medical Journal, Nov. 1935.)

$\mathrm{T}$ $\mathrm{HE}$ excuse that the diet of the peoples in the tropics suits them because they are used to it, has been adequately disproved (Leitch). Orr and Gilkes have traced the different physique and resistance to morbid conditions of the Kikuyu and Masai, to their different diets. McCarrison maintains that food is the paramount factor responsible for the contrast between the manly, stalwart and resolute races of Northern India and the poorly developed, toneless and supine peoples of the East and South. By feeding groups of animals on diets typical of the various tribes, he produced parallel physiques with corresponding resistance or susceptibility to infection. Magaw suggests three main forms of deficiency-shortage of food as a whole, shortage of available protein, shortage of vitamins; and that many millions of the inhabitants of the tropics live on the border line of starvation, that when harvests are bad they may suffer from actual starvation.

Avitaminosis B is one of the predominating deficiencies. Leitch refers to this particularly in Trinidad, Central Africa, Tanganyika, India, Straits Settlements and the Philippines. McCarrison stresses for India a diet rich in this vitamin, pointing out that a diet in which vitamin $B$ is not wholly lacking though insufficient for normal metabolism, leads to poor appetite, failure to increase in body weight, oractual loss, alimentary disturbances, disorders of the skin, symptoms referable to the malnutrition of the nervous system, and to intercurrent infections, which latter may lend wide variety to the symptomatology. Balfour agrees that the diet of Southern India is relatively poor in vitamin B, and adds that the wide prevalence of disease, the main aetiological factor of which is B avitaminosis, e.g. beriberi and pellagra, is a measure of the serious shortage of this vitamin. On the other hand Cramer and Mottram suggest that the nonappearance of beri-beri does not guarantee that the diet is adequately supplied. Variants are described in which one of the factors is probably vitamin B deficiency e.g., Wright's $\mathrm{A}$ and $\mathrm{B}$ avitaminosis disease of Sierra Leone, and Moor's retrobulbar neuritis associated with sore tongue and mouth, and occasionally concurrently pruritus scrotum. Grunfelder has identified a condition in Palestine of diarrhoea with nervous symptoms, relieved by vitamin B 1, and Corkhill 
refers to a pellagroid condition in the Sudan on a wholly millet diet, absent when the diet contained milk.

Leprosy is common in those countries where poverty and a low standard of living prevail (Muir). Rogers and Muir attribute the prevalence of leprosy in the Middle Ages to a deficiency of fresh animal and vegetable food. Muir and Santra, and Lowe, connect the high incidence of leprosy in some areas in India with dietary faults. Gupta says that where the standard of living is the poorest, the incidence of leprosy is the greatest. Whilst more than one factor may be involved, leprosy has disappeared from countries where the standard of living has improved, and remained where the standard has changed but little.

Had Hutchinson emphasised what fish eaters did not eat, he might have anticipated the present attention to diet in the treatment of leprosy. Rogers and Muir regard deficient diet as predisposing to infection, and precipitating lepra reaction. Muir has described thirty Chinese lepers in Calcutta, who with one exception recovered when the diet was improved and had then better health than they had had for many years.

The procuring of a plentiful and varied food supply is of extreme importance (Rogers and Muir, Muir, Low, Cruikshank). Lampe provides food free to the children in Surinam, not as a social measure only, but hoping that good nourishment will lead to improved health and resistance, and thereby to subsidence of the symptoms. Kiel writes "In view of the limited pathogenicity of the leprosy bacillus, it may be said that the development and course of the disease is not influenced so much by the virulence of the germ as by the capacity of resistance and state of immunity of the patient. These are in close relationship with the nutritional state especially during childhood . . . Leprosy is primarily a disease of poverty, and an increase in the standard of living automatically brings a retrogression of leprosy morbidity." Kiel has deduced a dietetic treatment, and illustrates his results by photographs of a patient of nine years, showing marked improvement in lesions of the face as a result of four and a half months dietetic treatment.

The traditional treatment of leprosy is being regarded less favourably. Lowe believes none of the medicaments used in leprosy have any specific effect. It is certainly doubtful whether injections of hydnocarpus preparations given casually to outpatients, without the control possible in institutions, is of any value at all, unless it be psychological. Attempts have been made to find alternatives, e.g., various dyes and mercurochrome, and Ryles maintains that brilliant 
green is at least as efficacious as the usual medicaments. Lie, who maintained isolation was largely responsible for the disappearance of leprosy from Norway, gave up the usual treatment for dietetic measures. Rodriguez has shown that it does not necessarily follow: the earlier the case the better the result-as far as chaulmoogra oil is concerned, and Cochrane adds that it is more than ever being realised that the solution of the problem of treatment in leprosy will be found in the metabolic processes of the body.

The general importance of milk has been attested by Orr and Gilks, Bonin, McCulloch and others. Atkey has related the consumption of milk to the lower incidence of leprosy. Badenock and Byrom obtained clinical improvement in lepers with a rise in serum calcium when the patients were transferred to a hospital milk diet, commenting that the rise in blood calcium might have been due to increased intake, but the clinical improvement not simply to that, but to the other factors in the milk. (Milk contains both vitamins A and B). Cook insists that leprosy is a deficiency disease, discountenancing $M$. leprae altogether, and referring particularly to vitamins $A$ and $B$. Lowe records pellagra in the Leper Settlement at Dichpali, Hyderabad, although it occurs in the ordinary population too. Wilson describes forty-two cases of "Red Disease "- a pellagroid-in Leper Settlements in Korea, rarely met outside and clearing up with pork and cod liver oil added to the diet. (Such meat contains seven to eight times the amount of vitamin B in beef muscleKemmerer and Steenbock). Mellanby associates A avitaminosis with conditions previously ascribed to B avitaminosis. Such evidence as there is seems to focus attention upon B and possibly $\mathrm{A}$ avitaminosis.

There are possibly analogies between beriberi, pellagra and leprosy. Their distribution is similar or overlaps. They have a long "incubation" period. The symptoms of chronic beriberi and nerve leprosy are those of a progressive peripheral neuritis, affecting both the motor and sensory nerve endings. In beriberi the earliest changes in the nerve endings have been described by Woolard, and Tsunoda and Kura, and are reversible. The earliest changes in leprosy are those detailed by Muir and Chatterji. The prodromal symptoms of leprosy, exemplified in the records following, suggest there may be earlier changes, but a description of these is not available because of the difficulty of diagnosis in the "prodromal" stage, and of obtaining the necessary material. Such changes as Muir and Chatterji describe are remarkable for their absence of Hansen's bacillus, and to account for 
this they postulate ultramicroscopic forms, and modify their theories of the spread of infection.

Pellagra and leprosy are characterised by alternating attacks and remissions over a period anything up to twenty years. In pellagra the alimentary tract is characteristically involved; in leprosy anatomical changes are not so common, but functional disturbances are. In pellagra there is early mental depression and dementia is frequent; in leprosy dementia is rare and then usually coincident, but mental depression is common and may lead to acute melancholia. The first visible lesion in leprosy is usually a depigmented patch, with alterations in sensation, but no demonstrable bacilli, and indicates changes in the peripheral nerve supply. As the process extends to the skin, it is accompanied by a dermatitits, with the usual signs of inflammation, swelling, hyperaemia, and an exaggeration of the subjective sensations. The skin lesions in pellagra are symmetrical, but are not always limited to exposed areas. Shelley and Mellanby maintain that they are neurotropic, and Mellanby says that this must be given first consideration in settling the aetiology. In both diseases there are alterations of pigmentation in the affected areas, with thickening and finally atrophy and wrinkling.

Apart from the classical syndromes certain symptoms follow deprivation of vitamin $\mathrm{B}$, namely-anorexia, loss of weight and interference with growth, lesions and functional changes in the alimentary tract, and oedema. The loss of desire to partake of the deficient food may be a morbid phenomenon, or an attempt by the organism to liberate by starvation and tissue, wasting the body stores of the lacking vitamin (Kon and Drummond). Both B 1 and B 2 stimulate appetite, in the presence of each other. Limitation of both leads to impairment of utilisation of food before the loss of appetite; if only one factor is lacking the order of events is reversed (Griffiths and Graham). Peters regards the loss of appetite as secondary to the internal starvation, and a reflection from tissue cells which have lost their rightful powers of assimilation. Vitamin B appears to have a definite effect on weight and growth, and it has been shown (Dennett, Hoobler, Bloxsam, Summerfeldt, Morgan and Barry) that infants fed on diets rich in vitamin B gained in weight and growth considerably more than controls on normal food. Various lesions in the alimentary tract have been described, whilst atony and delay in emptying have been proved by Gross and by Rowlands and Browning. Farnum has shown a diminution of the total and free acidity of the gastric secretion in beriberi; Gross, a diminution of bile 
pigments and the number of seybala in B deficient animals; and Cramer and Mottram that vitamin B greatly modifies food absorption and has an intensely stimulating effect on the functional activity of the whole digestive tract. The association of idiopathic oedema is less certain.

Rogers and Muir refer to abdominal disease in lepers, particularly incomplete digestion or stasis following on some present or former inflammation, and to chronic constipation, which latter is very common, due to "dilatation of the colon, chronic ulceration of the bowel, endocrine insufficiency, unsuitable diet and other causes," adding that regulation of the bowels by suitable diet is necessary, and that purgation is one of the favourite remedies in India for leprosy. Cochrane also stresses the importance of constipation, very often unrecognised. It is possible that an unsuitable diet may be unsuitable because of its subminimal vitamin content, and that the indigestion and stasis and even inflammatory changes may be due to this deficiency.

The following observations were made upon forty-one children and twenty-five adults, to see if the addition of vitamin $\mathrm{B}$ to the diet resulted in any marked improvement. Careful enquiries were made into the family histories, previous medical histories, and into the mode of onset. The diet of the patients was elicited, with special reference to vitamin $\mathrm{B}$ containing accessories. The sedimentation index was taken periodically, and the temperature and weight records carefully preserved.

Family Histories.

Children $\%$ Adults $\%$

Relatives infected and lepers in the compound

Relatives infected only $\quad \cdots$

Relatives not infected but lepers in the compound ... ...

No source of infection known

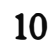

11

24.4

26.8

6

24

$\begin{array}{ll}4 & 9.8\end{array}$

$16 \quad 390$

3

12

Average percentages admitting knowledge of source of infection

Average percentages not admitting knowledge of source of infection

The difference in the groups may be due to their smallness; in the case of the children, contacts would be in a limited and more intimate circle. Stein's figures are $53.3 \%$ and $46.7 \%$, and he uses them to show the danger of contact and the importance of isolation. The usual emphasis is upon the large proportion admitting contact. Assuming that the number admitting contact is less than the actual, there are still a large number of cases in which the prolonged intimate 
contact, usually regarded as essential, is extremely doubtful, and especially such contact with an infective leper.

Previous Medical Histories.

In a few cases the first symptoms immediately followed some illness e.g., yaws. The majority of the population, however, suffers from yaws, malaria, helminth infections, etc. etc., and the histories of the lepers, except in a few cases were not notoriously worse than those of patients seen in a general hospital. Having recognised the predisposing effect of previous illness, the question arises in a group of people, all of whom have had the diseases common to their country, and only the same degree of casual contact with infective lepers, what other factors determine the onset of leprosy?

Histories of Onset.

Certain subjective sensations were common to practically all cases; in many before the appearance of patches. They were referred (1) to the whole body; (2) to the site of a future lesion; (3) to a site in which a lesion had not as yet developed. They included paraesthesia-"crawling," "tingling," " burning," " irritation " and " a feeling of insects in the skin "; hyperaesthesia-pain in one place or all over the body on the slightest touch; paint-“ "biting " a gnarling or gnawing pain, pain in the course of the nerves akin to neuralgia or toothache, and pain in the deeper structures; muscle weakness referred to as " inability to grip," and occasional "cramps"; numbness and anaesthesia, both macular and acroteric. In some respects the sensations resembled the description of chronic ergotism- " itching and tingling, and a sensation of insects running over the skin followed by numbness and local anaesthesia " (Hale-White). Such prodromal symptoms may be dismissed as " general "; lesions do develop, however, in some of the areas to which symptoms are referred. It seems reasonable to conclude they are due to early pathological changes in the nerve endings, or to some altered blood condition, metabolic or toxic, or both.

Six cases emphasised muscular rather than sensory symptoms, four definite symptoms and irregularities referred to the digestive tract. Constipation and minor digestive disturbances ar e frequent, but were not mentioned more often in the present series, because such conditions are more or less ' natural,' and because leading questions were not asked.

\section{Diets.}

The staple diet resembled that of the ordinary population -yam, cassava, palm oil etc. etc. The vitamin B accessories 
were okra, pawpaw, plantain and bananas, beans, groundnuts pumpkins and oranges. Maize was eaten, but when roasted over an open fire and the exterior charred, even the heat stable content of vitamin B must become considerably diminished. In the absence of exact quantitative determinations of various foods, any standard of comparison is arbitrary and relative. The diet was classified as "marginal" if it included a reasonable quantity of one or other of the vitamin B accessories daily; " inadequate " if it did not; and " adequate " if it contained more than the "marginal " diet. The cases in which data were obtainable were grouped as follows :-

$\begin{array}{lcccc} & \text { Adults } & \% & \text { Children } & \% \\ \text { Adequate } & 12 & 48 & 23 & 57.5 \\ \text { Marginal } & 4 & 16 & 8 & 20 \\ \text { Inadequate } & 9 & 36 & 9 & 22.5\end{array}$

On this basis the figures suggest more inadequacy among the adults, but the needs of the children are proportionately greater. Their real inadequacy is seen by comparison with the diet suggested for lepers by Kiel and by McCulloch's diet for the population of Nigeria, the former being an optimum and the latter a minimum. The absence of dairy produce makes the emphasis on vitamin $\mathrm{B}$ accessories more important than ever. This and the suggestion of Plimmer, Raymond and Lowndes, that in order to supply sufficient B 1, the diet must be composed of $60-80 \%$ of foodstuffs in the fresh state (vegetables and fruits), amounts impossible for man to consume, make it likely that those described as adequate may be doubtful, that in many cases the intake of vitamin B must have bordered on the minimum, in some cases not reaching it, and that when the accessories were out of season the majority were taking less than the minimum.

\section{Sedimentation Index and Temperature Records.}

It was thought that if a vitamin B deficiency influenced the invasion of $M$. leprae, vitamin $B$ added to the diet would lead eventually to a general improvement reflected in the sedimentation index; those with extra vitamin B would take more active treatment than those without, with less temperature and sedimentation index reaction, and those with extra vitamin $B$ not having active treatment would show a slower rate of sedimentation than those having neither extra vitamin B nor treatment.

The children were divided as follows :

1. Those receiving vitamin $B$ and injections. 
2. Those receiving vitamin $B$ only.

3. Those receiving injections only.

4. Those receiving neither vitamin B nor injections.

All had been having treatment up to November 30th, 1933; they were given a holiday in December, and in January 1934 treatment was resumed with Groups 1 and 3, and vitamin $\mathrm{B}$ was given daily to Groups 1 and 2 . At the end of January it was seen that this was not an effective comparison. The children were of different ages and physique, in different stages of disease, with, therefore, different maximum dosages and different tolerations for the drugs. For the groups having injections the only comparisons that could be made were the percentages of the maximum given, and since the ages had to be guessed, the maximum and the percentage of the maximum could only be an approximation. The matter was further obscured by injections being prevented even when the S.I., or the temperature was favourable, by pain at the site of injection previously given. It was then decided to regard each case individually, and at the end of January no further active treatment was given.

Temperatures were taken morning and evening, and tables drawn up for comparison, for each month for each patient.

The preparations of vitamin B used were Marmite and an extract of rice polishings prepared by Messrs. Ferris Ltd., of Bristol. The latter was only used in a few cases.

The results did not show any definite improvement, but there is evidence that the S.I. is extremely sensitive. Children with a comparatively mild disorder, frequently run a much higher temperature than adults. McKenzie says that the S.I. is influenced by state of debility not amounting to actual disease, and that it appears to be a very delicate expression of debility. Iswariah and Naiv maintain that the S.I. does not give a reliable indication of treatment. Paras, Lagrosa and Ignacio state that it shows no regular correspondence with the counse of the disease, except that a high index is the rule in reaction cases. The temperature of any patient and the S.I., which latter is more sensitive than the temperature, depend on a number of factors. In sanatorial work in England the exercise of every patient is regulated. Recurrent pyrexia can be controlled by decreasing exercise and increasing the periods of rest. With primitive people, and children especially, the problem is more involved, for intelligent co-operation is not available. The better he feels, the more the patient wants to move about, and does. 
Weight Records.

The cases were divided into groups according to changes in weight after the exhibition of vitamin $\mathrm{B}$.

Group A.-The cases in which the administration of Vitamin B concentrate was coincident with an improvement in the weight, and in which it was thought that the vitamin B concentrate was the factor responsible.

Group B.-Cases in which the vitamin B concentrate was associated with some improvement, but not so great as in Group A, and in which the vitamin B concentrate may have been the factor responsible.

Group C.-Cases in which the administration of the vitamin B concentrate was not associated with any improvement.

Group D.-Cases in which some complication or exacerbation of the disease seriously interfered.

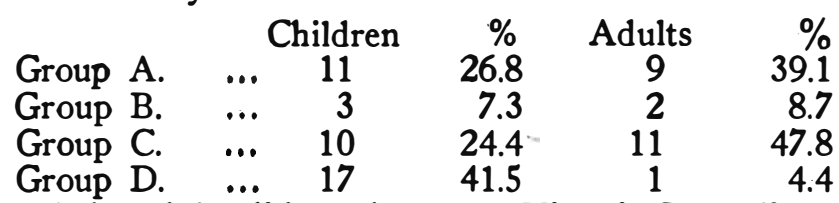

Two of the adults did not have any Vitamin B at all and did not show any weight change. The following are the weight records of those in group A. In some cases the changes are proportionately small, in others large. Weight Records for the adults were not available before February as it was only then decided to include them for additional evidence.

$$
\begin{aligned}
& ,=2 \text { drachms Marmite daily } \\
& "=4 \text { " }=1 \text { " }=1 \\
& r=\text { Rice Extract." }
\end{aligned}
$$

\begin{tabular}{|c|c|c|c|c|c|c|c|c|c|}
\hline $\begin{array}{l}\text { No. of } \\
\text { Case }\end{array}$ & $\begin{array}{l}\text { June } \\
\text { 30th }\end{array}$ & $\begin{array}{l}\text { July } \\
\text { 31st }\end{array}$ & $\begin{array}{l}\text { Nov. } \\
\text { 30th }\end{array}$ & $\begin{array}{l}\text { Dec. } \\
\text { 31st }\end{array}$ & $\begin{array}{l}\text { Jan. } \\
\text { 31st }\end{array}$ & $\begin{array}{l}\text { Feb. } \\
\text { 28th }\end{array}$ & $\begin{array}{l}\text { Mar. } \\
\text { 31st }\end{array}$ & $\begin{array}{l}\text { April } \\
\text { 30th }\end{array}$ & $\begin{array}{c}\text { May } \\
\text { 31st }\end{array}$ \\
\hline $\begin{array}{r}3 \\
8 \\
10 \\
11 \\
15 \\
17 \\
18 \\
23 \\
31 \\
34 \\
42 \\
45 \\
48 \\
49 \\
52 \\
55 \\
62 \\
63 \\
65 \\
67\end{array}$ & $\begin{array}{l}934 \\
768 \\
604 \\
74\end{array}$ & $\begin{array}{l}86 \\
85 \\
841 \\
67 \\
66\end{array}$ & $\begin{array}{c}105 \\
92 \\
90 \\
86 \\
97 \\
86 \\
781 \\
67 \\
64 \frac{1}{2} \\
75 \frac{1}{2} \\
91 \frac{1}{2}\end{array}$ & $\begin{array}{c}105 \frac{1}{2} \\
94 \frac{1}{4} \\
90 \frac{1}{2} \\
86 \\
97 \\
86 \\
78 \frac{1}{2} \\
67 \\
64 \\
76 \\
93\end{array}$ & $\begin{array}{c}110^{\prime} \\
96^{\prime} \\
106^{\prime} \\
91^{\prime} \\
102^{\prime} \\
89 \frac{1}{2}^{\prime} \\
79^{\prime} \\
65 \frac{1}{2} \\
63 \frac{1}{2} \\
76 \frac{1}{2} \\
94\end{array}$ & $\begin{array}{c}1109^{\prime} \\
96 \\
109^{\prime} \\
90^{\prime} \\
107^{\prime} \\
86^{\prime} \\
79 \\
66 \frac{3}{4}, \\
655^{\frac{3}{4}} \\
75 \frac{1}{2} \\
94 \frac{1}{2} \\
95 \\
126 \\
131 \\
123 \\
120 \\
151 \frac{1}{2} \\
129 \\
127 \\
115 \frac{1}{8}\end{array}$ & $\begin{array}{c}113^{\prime \prime} \\
9644^{*} \\
111 \frac{1}{2} * \\
95^{*} \\
112^{\prime \prime} \\
891^{\prime \prime} \\
83 \frac{1}{2} " \\
68 \frac{1}{2} \mathrm{r} \\
68^{\prime \prime} \\
79 \mathrm{r} \\
92 \frac{1}{4} \\
95 \\
125 \frac{1}{2} \\
130 \\
123 \\
120 \\
151 \frac{1}{2} \\
128 \frac{1}{2} \\
127^{*} \\
115 \frac{1}{2}\end{array}$ & $\begin{array}{c}115 \\
98^{*} \\
111 \frac{1}{2}{ }^{*} \\
95 \frac{1}{2} \\
112^{*} \\
90 \\
85 \frac{1}{2} \\
70 \mathrm{r} \\
70 \frac{1}{2} \\
78^{*} \\
994^{*} \\
984^{*} \\
126 \\
131 \frac{1}{2} \\
123^{*} \\
120^{*} \\
153 \frac{1}{2} * \\
129 \\
127 \frac{1}{2} \\
116^{*}\end{array}$ & $\begin{array}{c}116 \\
106^{*} \\
109 \\
97 \frac{1}{2} \\
112^{*} \\
92 \\
85 \frac{1}{2} * \\
72 \mathrm{r} \\
66 \frac{1}{2} \\
80^{*} \\
993^{*} \\
107^{*} \\
128 \frac{1}{2} \\
135^{*} \\
130 \frac{1}{2} * \\
122 \frac{1}{2} * \\
156^{*} \\
134 \frac{1}{2} * \\
131 \frac{1}{2} \\
118^{*}\end{array}$ \\
\hline
\end{tabular}


The increased weights were not due to increased availability of food as they coincided with the period when food was becoming dearer and less varied.

If the children and adults are taken collectively, and Group D excluded, the percentages become-A 43.4; B 10.9; D 45.7.

\section{Cases of particular interest.}

The number of cases chosen was relatively small, because of the cost of the preparations used, and no special grant being available. Even so it is not possible to give details of all. In every case an attempt was made to ascertain the patient's own opinion, and one was surprised to discover a number of them maintaining that the " new medicine" was making them hungry.

The following cases were of special interest:-

Case 4. Brother probably sole source of contact. Diet inadequate. Pain referred to the left calf muscle and Achilles tendon. Had a history of digestive disturbances-no change in weight, but had nerve reaction. Patient believed that the Marmite was responsible for the decrease in his pain, but there was no evidence of this as he was being treated for nerve pain.

Case 8. Contact very remote. Previous medical history contained only colic and headache. Onset with pain and weakness in the leg muscles. Gave history of 'digestive disturbances.' There was improvement with Marmite, with increase in weight, no return of the 'digestive disturbances' and the patient said he felt better.

Case 10. Contact very remote. Previous medical history contained only yaws and influenza. The onset was with muscle pains, weakness and cramps. Diet was inadequate. At the end of November he seemed to be very poorly. His hair had lost its normal lustre, and his skin was a dirty brown colour, covered with a fine branny desquamation. He seemed to have given up all hope, and there seemed to be very little indeed. The large gain in weight was associated with other pronounced changes in his appearance. The improvement was almost dramatic. Cod Liver Oil and Thyroid Extract had failed. Patient's comments endorsed the obvious improvement.

Case 17. No contact. Previous medical history-Nil. Diet inadequate. Had symptoms referred to the muscles.

Case 43 . Contact very remote, yet was a very acute nodular case. Diet inadequate. Previous medical history only contained malaria. After giving Marmite there was a small increase in weight, but the patient said he had more energy and felt a lot better.

Case 45. Contact remote. Previous medical history only contained yaws. Diet marginal. Had swelling of the legs in the wet season, pre-harvest period. He improved with Marmite, with increase in weight. Patient said he felt a lot better and was hungry.

Case 48. Contact remote. Previous medical history only contained yaws. Diet inadequate-improved with Marmite.

Case 50. Contact remote. Previous medical history-nil. Diet inadequate. Had symptoms referred to the miscles. 
Case 52. Contact remote. Had oedema prior to the harvest. Previous medical history-nil. Complained of loss of grip. Improved with Marmite with increase in weight.

Case 59. Contact not intimate. Previous medical history contained malaria, and enlargement of the spleen due to malaria. Diet inadequate. Complained of indigestion, 'irritation in the skin, and oedema. These disappeared with Marmite, and he was very emphatic about the improvement, but no improvement in weight.

Case 60. Contact remote. Previous medical history-nil. Diet inadequate.. Complained of stiffness in the leg muscles, and after gripping with the hands lost the use of them.

Inferences are not limited to the above cases, but they emphasise some of the facts already discussed. Their contact with lepers was not intimate, but only casual. There was little in their medical histories except possibly Case 59, to suggest any marked debility; their diets were seasonal, and judged by an arbitrary standard were at the best bordering on the minimum requirements of vitamin $B$; they showed symptoms that occur with $\mathrm{B}$ avitaminosis, and with the exception of Cases 4, 50 and 60 (who were in a state of reaction). there was some indication of improvement when vitamin $B$ was added to their diet.

\section{DISCUSSION.}

Theories are still being advanced which conflict with the more or less universally recognised one of vitamin B deficiency as the true course of Beriberi. Bernard, Matsumara, Cannon and others support an infective or toxic theory. McGaw, Chick and Bigland believe that there is some other factor in addition to avitaminosis. Susman suggests a blood-borne infection in pellagra, acting through the thyroid gland. Shelley believes the erythema is trophic, and the cause microbic or an intoxication. The Medical Research Council's Report suggests the possibility of maize containing a positive pellagra producing factor, operative in the absence of the pellagra preventative factor. Chick suggests pellagra is caused by a toxic substance derived from maize diets, which can be corrected by sufficient good protein or perhaps by sufficient vitamin B 2 accompanying the good protein.

Although many attempts have been and are being made to cultivate $M$. leprae, the lack of a susceptible animal for innoculation and the long incubation period, which may be anything from six months to five years, render the confirmation of apparent cultures by the usual methods extremely problematical. One of the most striking features of leprosy is its strict limitation to man, and the failure of attempts to transmit the disease to experimental animals. Jeanselme 
concludes that so far only some multiplication of the organism in transplanted living tissue, has been obtained outside the human body, but no true sub-cultures apart from living cells. Only localised self-healing lesions have been obtained in monkeys etc., but no generalisation of the disease as in human leprosy. Douglas suggested that if it was desired to infect animals, they should be fed on a vitamin deficient diet. Kobashi attempted to infect mice, rats and guinea-pigs, and in summarising his results says that the injected leprosy bacilli were present in the internal organs more frequently and persisted longer in animals in a condition of avitaminosis than in the control animals. $\mathrm{He}$ believes that this confirms a close relationship between vitamins and a disposition to susceptibility to leprosy infection. This susceptibility can be increased by vitamin deficiency. It appears that vitamin $B$ has the closest relation and vitamin $A$ less, and that vitamin $C$ has no relation at all. As the animals used were not ordinarily susceptible to leprosy infection, Kobashi helieves that this shows the possibility of increasing susceptibility by avitaminosis.

Where lepers give evidence of contact, especially in childhood, the contact has often been within the limits of their own families. The emphasis is then placed unon the prolonged intimate contact that takes place (Lowe). Children are particularly susceptible. It is more likely that within a family circle the same dietary conditions will be found, and as suggestions have been made associating leprosy with avitaminosis $\mathrm{B}$, it is interesting that Bray has shown, that adding vitamin $B$ to the mothers' diet decreased the infant mortality, and that Bennett, believing that breast milk does not always contain the optimal quantity of vitamin $B$, suggests in the interest of the child that this should be added to the diet. This is of added importance when it is remembered that in primitive races children are breast-fed for anything from one to three years.

Cooke says "Omitting minor manifestations of this disease, which it is difficult for modern medical knowledge to reconcile with the established views, we have sufficient and efficient reasons for doubting the correctness of the established views on leprosy... These serious difficulties justify us in trying to find some other angle from which to view the disease." $\mathrm{He}$ advances the hypothesis that leprosy is a deficiency disease, and that the acid-fast rods known as Hansen's bacilli are probably due to a metamorphosis of the tissues, changes of staining capacity which are the result of the disease and not the cause of it. 


\section{CONCLUSIONS.}

1. Tropical dietaries are unsatisfactory and B avitaminosis is common. Leprosy is endemic where dietary insufficiencies exist. Faulty dietaries predispose to leprosy infection. Dietetics is becoming prominent in the treatment of leprosy, and in some cases in replacing traditional methods.

2. Analogies between beriberi, pellagra and leprosy have been suggested, and symptoms associated with $B$ avitaminosis enumerated. Reference has been made in the records to cases of particular interest.

3. $48.5 \%$ of sixty-six cases of leprosy denied knowledge of possible sources of infection. Given "suitable soil," infection may take place with only casual contact.

4. The previous medical histories were very little different in the majority of cases from the medical histories of uninfected natives.

5. The prodromal subjective sensations may be due to earlier pathological changes than have been described, or to some altered blood condition, either metabolic or toxic, or to both.

6. The vitamin $B$ content of the diets bordered upon an arbitrary minimum, in some casses not reaching the minimum. It is doubtful whether the 'adequate' diets were adequate all the year.

7. $43.4 \%$ of the patients gained in weight when vitamin $\mathrm{B}$ was added to their diet.

8. In beriberi and pellagra, toxic, infective and deficiency theories have been advanced, and opinion tends to a composite aetiology. It is possible that a similar composite aetiology may exist in leprosy.

9. As deficiencies existing among lepers may be coincident, corresponding with similar deficiencies among the general population, it is hoped to continue the work, using preparations of both vitamins $\mathrm{A}$ and $\mathrm{B}$, and comparing with a series of controls chosen from non-lepers At the same time it is hoped to eliminate any effect due to the haemopoietic factor in Marmite.

10. Since the suggestion has been made that the effect of injections of chaulmoogra oils is purely nutritive (Low), an investigation into the vitamin content of these oils and their preparations would be of value.

\section{REFERENCES.}

Atrey, O. F. H., Int. Jour. Lep. II. 2. 193, 1934.

Banenoch, A. G. and Byrom, F. E., Trans. Roy. Soc. Trop. Med \& Hyg. XXVI, 3 253, 1932. 
Balfour, M., Proc. Roy. Soc. Med. 27, 4-473, 1934.

Bernard, N., Trop. Dis. Bull. 29. 609, 1932.

Bigland, A. D., Trop. Dis. Bull. 31. 5. 293, 1934.

Bloxsam, A. P., Journ. Amer. Med. Assn. 93, 1929.

Bray, G., Trans. Roy. Soc. Trop. Med. \& Hyg. XXII 9, 1928.

Browning, E., Monograph of Pickett-Thompson Res. Lab. I.

Browning, E. and Rowlands, M. J., Lancet I, Jan. 28, 180, 1928.

Bonin, G., Nutr. Abst \& Rev. I, 3, 1935. 1932.

Cannon, A., Trans. Roy. Soc. T. M. \& H., XXIII, 263, 1929.

ChIck, H., Proc. Roy. Soc. Med. 27, 4, 473, 1934.

Cochrane, R. G., Lep. Rev. V3 100. Leprosy Symp. Diag Tr. and Prog. B.E.L.R.A., 2nd Edn., 1934.

Cook, L., Leprosy Rev. IV. 4, 166, 1933.

CoRKhILl, N. L., Lancet 225. 1387, 1934.

Cramer, W. \& Mottram, J. C., Lancet II. 1090.

Cruickshank, C., Lep. Rev. III, I, 3.

Dennett, R. H., Journ. American Med. A.ssn. 92, 769, 1929.

Douglas, S. R., Trans. Roy. Soc. Trop. M. \& H. VVIV, 6, 557, 579, 1931.

FARNum, M. B., Arch. Int. Med. 37n, 212, 1926.

Griffiths, W. H. \& Graham, C. E., Proc. Soc. Exp. Biol. \& Med. 28. 1086, 1930/1, J. Bio. Chem. 92. Proc. LXIII.

$$
\text { do. 97. Proc. VII. }
$$

Gross, L., Jour. Path. \& Bact. 27. 27, 1924. Jour. Physiol. 57, Proc. LX.

GrunfeldeR, B., Nutr. Abstr. \& Rev. IV. 2, 1713, 1934.

GuPTA, U. P. do.

II. $1,558,1932 / 3$.

Hale-White's Materia Medica-Churchill-21st Edn. 1932.

Hoobler, B. R., Journ. Amer. Med. Assn. 96, 625, 1929.

Iswariah, V. \& NaIr, V. G., Trop. Dis. Bull. 31. 8, 551, 1934.

Jeanselme, Ed. 2.La Lepre Doin et Cie Paris; Bull. Trop. Dis. 31, 10, 754.

KIEL, E. G., Int. Jour. Lep. I, 4, 393.

Kemmere', A. R., \& Steenbock, H. Journal Biol. Chem. 103, 353, 1933.

Kobashi, S., Int. Journ. Lep. I. 3, 354, 1933.

Kon, S. K. and Drummond, J. C., Biochem. Journ. XXI, 632, 1927.

Lampe, P. H. J., Lep. Rev. III, 4, 147, 1932.

LeITCH, J., Dietetics in Warm Climates-Harrison \& Sons, Ltd., 1930.

Low, C., Trans. Roy. Soc. T. M. \& H. XXIV, 6. 577, 579, 1931.

LowE, J., Int. Journ. Lep. I, 3, 341, 1933. Trop. Dis. Bull. 29, 94, 1931 ; T.D.S. $31,26,1934$.

Magaw, J. W. B., Lancet, Jan. 11; 79, 1930.

Matsumara, S., Journ Amer. Med. Assn. 192, 1325, 1929.

McCarrison, R., Nutr. Abst. \& Rev. II. 11-1, 1932/3.

McCulloch, W. E., Rep. upon Diet in Schools-Gov. Printer, Lagos, 1933.

McKenzIE, A., Lep. Rev. IV, 2, 49; IV.3, 99, 1933.

Mellanby, E., Nutrition and Disease-Oliver and Boyd, 1934.

Morgan, A. F. \& Barry, M. M., Journ. Amer. Med. Assn. 94, 1952. 1930.

Muir, E., A Syst. of Bact. in Rel. to Med... Leprosy Vol. V, 345, 1930, Med. Res. Council.

Ind. Journ. Med. Res. 51, I 1927; Int. Journ. Lep. I 4, 407. 1933;

Trans. Roy. Soc. T. M. \& H. XXV. 2.87. 1931.

Muir, E and ChatterjI, S. P., Int. Journ. Lep. I 2, 129, 1933.

OrR, J. B. and Gilkes, J. M., Med. Res. Counc. Spec. Rep. Ser. 155. H.M.S. Office, 1931.

Paras, E. M., Lagrosa M., and Ignacio., Int. Journ. Lepr. II. Io 1934, 123.

Peters, R. A., Journ. State Med. Lon. 38.3, 1930.

Plimmer, R. H. A., Raymond, W. H., and Lowndes, J., Nutr. Abstr. \& Rev. I, 3, 2447.1932.

Rodriguez, J. Lep. Rev. V 3, 102. 1934.

Rogers, Sir L. \& MUir, E., Leprosy-John Knight \& Sons, London, 1925.

Rhyles, C. S., Lep. Rev. IV. 3, 113, 1933.

SANTRA, I., Ind. Med. Gaz. 62. 442, 1927.

Shelley, H. M., Trans. Roy. Soc. Trop. Med. Hyg. XXIV, I p.9, 1930.

Stein, A. A., Int. Journ. Lep. I, 3, 309, 1933.

Summerfeldt, P., Journ. Amer. Med. Asson. 98, 1593, 1932.

Susman, W., Trans. Roy. Soc. Trop. Ned. \& Hyg. XXIV, I. 23.

Wilson, R. H., Int. Journ. Lep. I. 4, 505, 1933.

WOOLARD, H. H., Journ. Anat. 61, 283. 1927. 